\title{
Influência da Forma das Encostas na Suscetibilidade à Erosão na Bacia Hidrográfica do Rio Claro (Santa Rita do Passa Quatro, SP)
}

\begin{abstract}
Influence of slope shape on susceptibility to erosion in the Rio Claro watershed (Santa Rita do Passa Quatro, SP)
\end{abstract}

\author{
Thamiris Cristina Costa Basilio ${ }^{1}$ \\ Jaqueline Tomiê Fujimoto ${ }^{1}$ \\ Thiago Lopes ${ }^{1}$ \\ Gustavo Augusto Mendonça Asciutti ${ }^{1}$ \\ Reinaldo Lorandi ${ }^{2}$ \\ José Augusto de Lollo ${ }^{3}$
}

Recebido em agosto de 2018. Aprovado em dezembro de 2018.

\begin{abstract}
RESUMO
A erosão é conhecida como um fenômeno que gera graves consequências ao ambiente, se tornou uma preocupação global e foco de muitos estudos que buscam prevenir ou controlar seus efeitos. A bacia hidrográfica do Rio Claro, situada na região nordeste do estado de São Paulo é constituída predominantemente de materiais inconsolidados de textura arenosa e compreende uma área de $251,91 \mathrm{~km}^{2}$. Este trabalho investigou, na escala 1:50.000, a influência das formas das encostas na suscetibilidade à erosão acelerada dessa bacia, a partir de dois métodos análise: Processo Analítico Hierárquico (AHP) e o Método da Soma Ponderada (Weighted Sum - WS). Com base em um banco de dados ambientais pré-existente, foram gerados mapas e cartas intermediários e temáticos. Os resultados mostram alta concentração de registros de erosões ativas de grande porte nas áreas com declividades entre $2 \%$ e $10 \%$, compreendendo $1.55 \mathrm{~km}^{2}$ relevo composto por colinas médias côncavas e convexas, e presença de materiais inconsolidados derivados das Formações Quaternárias e Terciárias. Tais processos se
\end{abstract}

\footnotetext{
${ }^{1}$ Programa de Pós-Graduação em Engenharia Urbana, Universidade Federal de São Carlos, Brasil. Email: thamiris.basilio@gmail.com; jaquetomie.jf@gmail.com; thiago.lopes000@hotmail.com; gustavo_asciutti@yahoo.com.br

2 Professor Associado 3 da Universidade Federal de São Carlos, no Departamento de Engenharia Civil. E-mail: lorandir@gmail.com

${ }^{3}$ Professor Titular da Universidade Estadual Paulista Júlio de Mesquita Filho, na Faculdade de Engenharia de Ilha Solteira, Brasil. E-mail: ja_lollo@yahoo.com
} 
concentram em áreas classificadas como baixa e muito baixa suscetibilidade a erosão, segundo as duas técnicas utilizadas. Além da influência da textura arenosa e baixa compacidade dos solos, a concentração dos processos erosivos é controlada principalmente pela forma das encostas. Em termos percentuais, ocorrem mais processos erosivos nas áreas de colinas de perfil divergente côncavo, enquanto as maiores densidades de processos erosivos se localizam em áreas de colinas divergentes convexas e, secundariamente, nas colinas divergentes retilíneas.

PALAVRAS-CHAVE: Suscetibilidade à erosão. Forma de encosta. Bacias hidrográficas.

\begin{abstract}
Erosion, known as a phenomenon that causes serious consequences to the physical environment, has become a global concern and the focus of many studies in order to prevent or control its effects. The catchment area of Rio Claro, located in the northeastern part of the state of São Paulo, consists predominantly of unconsolidated sandy texture materials and comprises an area of $251.91 \mathrm{~km}^{2}$. The aim of this work was to investigate the influence of slope shapes on the analysis of susceptibility to the accelerated erosion of this basin at a 1:50,000 scale, by comparing two methods: Analytical Hierarchical Process (AHP) Technique and Weighted Sum (WS). Intermediate and thematic cartograms were generated from a pre-existing database. The regions with slopes between 2 and $10 \%$ comprise $1.55 \mathrm{~km}^{2}$ and are characterized as medium concave and convex hills, with the presence of unconsolidated materials corresponding mainly to the Quaternary and Tertiary Formations, where there is a predominance of large active erosions. The results show disseminated erosion processes in areas classified as low susceptibility and very low according to the two techniques. The concentration of the erosion processes is controlled by the shape of the slopes, particularly in the areas of medium hills with concave profiles, with sandy soil profiles and low compactness. In addition to the influence of sandy texture and low compactness of soils, concentration of erosive processes is mainly controlled slope shape. Major number of erosive processes occurs in concave divergent hills areas, while the highest densities of erosive processes are located in areas of convex divergent hills and, secondarily, in rectilinear divergent hills.
\end{abstract}

KEYWORDS: Susceptibility to erosion. Shape of slopes. Hydrographic basin.

\title{
Introdução
}

A erosão do solo é um fenômeno natural que pode acarretar em graves consequências para a humanidade. Há muito tempo, tal tema atraiu a atenção de muitos pesquisadores em relação às suas causas, progressão e controle, devido à extensão de suas áreas de influência que podem desfigurar o 
ambiente físico, alterando suas propriedades naturais (LOLLO e SENA, 2013).

Segundo Lal (2001), os principais fatores que influenciam na ocorrência e aceleração dos processos erosivos são o índice pluviométrico, a susceptibilidade dos materiais geológicos presentes (materiais inconsolidados), as formas de relevo e o uso e ocupação do solo. Diante de um cenário de tomada de decisão para o planejamento territorial e dos impactos causados por esse fenômeno natural, o estudo dos condicionantes do processo erosivo merece aprofundamento.

Diversos autores defendem o uso da bacia hidrográfica como unidade de organização e manejo dos recursos naturais (MENEZES, 2001; GARCIA, 2011; MORAES et al., 2016), para Ross e Del Prette (1998), estas são instrumentos importantes no planejamento e gestão; em função da integração entre o ser humano e o meio que o cerca. Cada bacia apresenta características distintas das vizinhas, sendo delimitadas por divisores de águas topográficos e freáticos. Assim, a bacia hidrográfica pode ser considerada uma unidade ideal de gerenciamento, apresentando limites considerados imutáveis, o que facilita o acompanhamento de alterações naturais ou antrópicas no seu interior (TAGLIARINI et al., 2015).

Segundo Dorici et al. (2016), a compreensão dos processos erosivos e de seus impactos é fundamental para a tomada de decisões de planejamento. Uma abordagem adequada à tal análise é a elaboração de cartas de suscetibilidade à erosão (PONS et al., 2007; MONTES e RUIZ, 2008; LOLLO \& SENA, 2013; GALHARTE et al., 2014 SCHEWE et al., 2014; TORRES et al., 2016).

As cartas de suscetibilidade classificam os terrenos quanto ao potencial de ocorrência de processos geológicos naturais e induzidos em áreas de interesse (PEJON, 1992; BITAR, 2015). Sua elaboração requer levantamento, tratamento e análise de informações ambientais de natureza e fontes variadas (COSTA et al., 2016). 
Dentre os processos de degradação ambiental, a erosão e a perda de qualidade dos recursos hídricos, são os impactos mais marcantes. No da bacia do Rio Clarinho (SP) intensos processos erosivos se instalaram, gerando grave degradação (GUERRERO et. al., 2016). He (2006) destaca que em ambientes tropicais úmidos, a intensidade dos processos hidrológicos e atmosféricos induz processos erosivos mais intensos.

A Bacia Hidrográfica do Rio Claro tornou-se objeto deste estudo por conjugar condições do meio físico que induzem importantes processos erosivos, inclusive a presença de uma voçoroca situada na porção nordeste da bacia. Assim, este trabalho buscou compreender a relação entre os atributos do meio físico e os processos erosivos nessa área, com enfoque na influência de atributos do revelo na suscetibilidade à erosão na bacia, baseada na comparação entre dois métodos de álgebra de mapas (soma ponderada e AHP), tendo como estudo de caso a Bacia Hidrográfica do Rio Claro.

\section{Caracterização da área de estudo}

A bacia hidrográfica do Rio Claro está localizada na região nordeste do estado de São Paulo. Possui uma área de $251,91 \mathrm{~km}^{2}$, grande parte dessa área inserida no município de Santa Rita do Passa Quatro e pequena parte no município de Porto Ferreira (Figura 1). As coordenadas geográficas que delimitam a bacia, no Datum SIRGAS 2000, correspondem coordenadas (UTM): 259533.00 m E, 7604055.00 m S (nascente do Córrego do Faveiro, tributário do Rio Claro) e 238041.00 m E, 7587540.00 m S (foz no Rio Mogi Guaçu).

A bacia do Rio Claro constitui parte da bacia do rio Mogi Guaçu UGRHI 09, a qual por sua vez integra a bacia hidrográfica do Rio Grande na Região Hidrográfica do Paraná (FEHIDRO, 2011).

Na região, há a presença de vegetação remanescente do bioma Mata Atlântica (predomínio da fisionomia floresta estacional semidecidual), e, em menor proporção, fisionomias características de Várzeas e de Cerrado (IF, 2010). 
Figura 1 - Localização da área de estudo

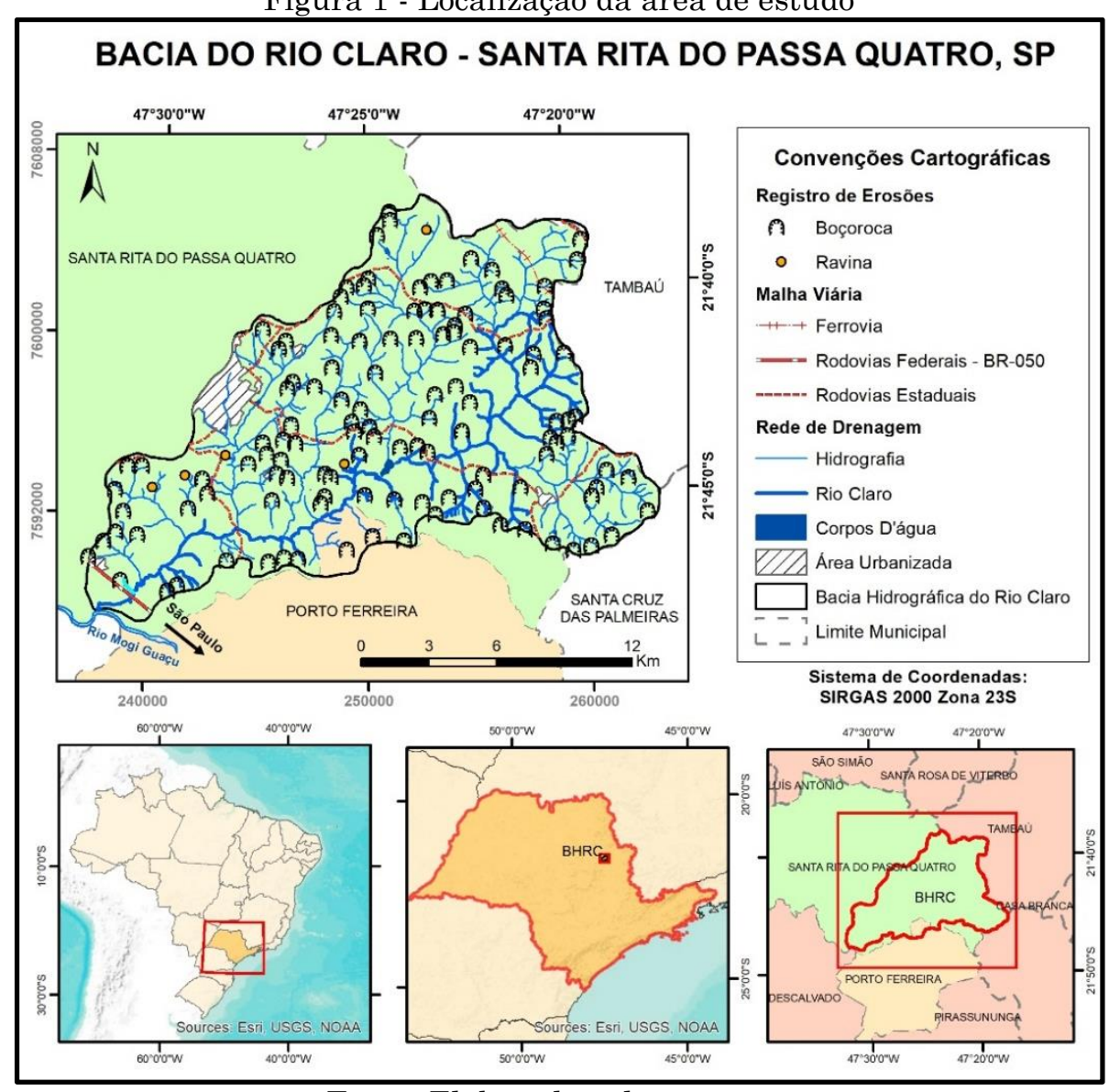

Fonte: Elaborada pelos autores.

Além desta cobertura vegetal, foram identificados diferentes tipos de uso e ocupação do solo, como atividades agropastoris (cana-de-açúcar, café, citricultura, pastagem, silvicultura), área urbanizada; e locais de mineração. Segundo Lorandi e Lollo (2016), o relevo é caracterizado por formas predominantemente denudacionais, essencialmente colinas médias e amplas, de topos tabulares, os vales apresentam entalhamento médio com menos de 20 metros. As altimetrias compreendem entre 500 e 700 metros com declividades médias entre $2 \%$ e $10 \%$.

No Mapa de Landforms elaborado por Lorandi e Lollo (2016), se observa a predominância de Colinas Médias Côncavas em 55,40\% da bacia, em áreas com declividades entre 5 a 10\%. Em 15,90\% da área ocorrem Colinas Médias Convexas, as quais representam a maioria dos divisores de água da bacia e algumas nascentes, com declividades menores que 5\%. As unidades 
restantes encontradas são Colinas Pequenas Convexas, Escarpas, Vales Amplos Abertos, e Vales Pequenos Fechados; ocupando 12,33\%, 7,50\%, 7,29\% e $1,39 \%$ da bacia, respectivamente.

As unidades litoestratigráficas presentes na bacia do Rio Claro são apresentadas no Quadro 1. Os arenitos pouco consolidados da Formação Santa Rita do Passa Quatro são os mais abundantes e abrangem $45 \mathrm{~km}^{2}$.

Quadro 1 - Unidades litoestratigráficas presentes na Bacia do Rio Claro

\begin{tabular}{|c|c|c|}
\hline Unidade & $\begin{array}{l}\text { Era e } \\
\text { Período }\end{array}$ & Descrição \\
\hline $\begin{array}{l}\text { Depósitos } \\
\text { Aluvionares }\end{array}$ & $\begin{array}{l}\text { Cenozóica; } \\
\text { Holoceno }\end{array}$ & $\begin{array}{l}\text { Ocorrem em planícies aluviais do Rio Claro e seus } \\
\text { afluentes principais. Depósitos de textura arenosa. }\end{array}$ \\
\hline $\begin{array}{l}\text { Formação } \\
\text { Piraçununga }\end{array}$ & $\begin{array}{l}\text { Cenozóica; } \\
\text { Terciário }\end{array}$ & $\begin{array}{l}\text { Composta por sedimentos areno-argilosos, pobremente } \\
\text { selecionados, com linha de seixos de quartzo, quartzito, e } \\
\text { fragmentos de limonita na base, sobrepostos de forma } \\
\text { discordante sobre a Formação Corumbataí. }\end{array}$ \\
\hline $\begin{array}{c}\text { Formação } \\
\text { Santa Rita do } \\
\text { Passa Quatro }\end{array}$ & $\begin{array}{l}\text { Cenozóica; } \\
\text { Terciário }\end{array}$ & $\begin{array}{l}\text { Constitui-se de areias em matriz argilosa, friáveis, sem } \\
\text { estruturas sedimentares, com cascalheira basal de seixos } \\
\text { predominantemente de quartzo. Na área estes sedimentos } \\
\text { apresentam grânulos de quartzo dispersos. }\end{array}$ \\
\hline $\begin{array}{l}\text { Intrusivas } \\
\text { Básicas } \\
\text { Tabulares }\end{array}$ & $\begin{array}{l}\text { Mesozóica; } \\
\text { Cretáceo }\end{array}$ & $\begin{array}{l}\text { São constituídos de soleiras e diques de magmatitos } \\
\text { básicos, de textura fanerítica e intensamente fraturados. }\end{array}$ \\
\hline $\begin{array}{l}\text { Formação } \\
\text { Botucatu }\end{array}$ & $\begin{array}{l}\text { Mesozóica; } \\
\text { Jura/Cretáceo }\end{array}$ & $\begin{array}{l}\text { Constituída de arenitos eólicos, de granulação fina a média, } \\
\text { composição quartzosa ( } 80 \% \text { ), e espessura variando entre } 20 \\
\text { e } 280 \text { metros. }\end{array}$ \\
\hline $\begin{array}{l}\text { Formação } \\
\text { Pirambóia }\end{array}$ & $\begin{array}{l}\text { Mesozóica; } \\
\text { Triássico }\end{array}$ & $\begin{array}{l}\text { Composta por arenitos fluviais, médios a finos, às vezes } \\
\text { bastantes argilosos. }\end{array}$ \\
\hline $\begin{array}{l}\text { Formação } \\
\text { Corumbataí }\end{array}$ & $\begin{array}{l}\text { Paleozóica; } \\
\text { Permiano }\end{array}$ & $\begin{array}{l}\text { Composta por folhelhos variegados, estando posicionada } \\
\text { entre as formações Irati (inferior) e Pirambóia (superior). }\end{array}$ \\
\hline
\end{tabular}

Fonte: Elaborada pelos autores 
Os materiais inconsolidados presentes na área são predominantemente arenosos, com exceção dos materiais residuais dos Magmatitos Básicos e da Formação Corumbataí, de granulometria argilosa (Tabela 1).

Tabela 1 - Caracterização geotécnica dos materiais inconsolidados (valores médios)

\begin{tabular}{|c|c|c|c|c|c|c|c|}
\hline \multirow{2}{*}{ Materiais Inconsolidados } & \multirow{2}{*}{$\begin{array}{l}\text { Área } \\
\left(\mathrm{km}^{2}\right)\end{array}$} & \multirow{2}{*}{$\begin{array}{c}\text { Espessura } \\
\text { (m) }\end{array}$} & \multicolumn{3}{|c|}{ Granulometria } & \multirow{2}{*}{$\begin{array}{c}\mathrm{K}_{20} \\
(\mathrm{~cm} / \mathrm{s})^{+}\end{array}$} & \multirow{2}{*}{$\begin{array}{l}\text { Mini } \\
\text { MCV }^{\#}\end{array}$} \\
\hline & & & $\mathrm{Ag}$ & $\mathrm{S}$ & $\mathrm{Ar}$ & & \\
\hline Quaternário & 15,87 & $<2,2-5$ & 5 & 4 & 91 & $6,110^{-3}$ & $\mathrm{NA}$ \\
\hline Res. Santa Rita do P. Quatro & 45,72 & $>5$ & 14 & 8 & 78 & $3,710^{-2}$ & $\mathrm{NA}^{\prime}$ \\
\hline Res. Piraçununga & 11,38 & $>5$ & 28 & 7 & 65 & $4,210^{-3}$ & $\mathrm{NA}^{\prime}$ \\
\hline Res. Botucatu & 17,65 & $<2,>5$ & 20 & 5 & 75 & $3,810^{-3}$ & LA \\
\hline Res. Pirambóia & 11,38 & $<2,>5$ & 24 & 6 & 70 & $7,110^{-3}$ & LA \\
\hline Res. Magmatitos Básicos & 26,48 & $<2,2-5$, & 47 & 17 & 36 & $4,910^{-4}$ & LG' \\
\hline Res. Corumbataí & 19,65 & $<2$ & 77 & 9 & 14 & $4,110^{-4}$ & $\mathrm{NG}^{\prime}$ \\
\hline
\end{tabular}

${ }^{*} \mathrm{Ag}=$ Argila, $\mathrm{S}=$ Silte, Ar. = Areia; +coeficiente de permeabilidade; \#Moisture Condition Value Fonte: Elaborada pelos autores.

O clima da área foi classificado como Clima Tropical Úmido-seco (4 ${ }^{\mathrm{a}}$ ) por Mendonça e Danni-Oliveira (2007), caracterizado pela ocorrência de 4 a 5 meses de seca durante a estação de inverno, chuvas concentradas no verão (outubro a abril) destacando-se os meses de dezembro, janeiro e fevereiro como os mais úmidos.

\section{Materiais e métodos}

Nesta investigação, foram empregadas as folhas topográficas do IBGE (1971), na escala 1:50.000 (Folhas Descalvado, Santa Rita do Passa Quatro e Luís Antônio), as formas de relevo, materiais inconsolidados, e uso e cobertura de Lorandi e Lollo (2016), e o registro de processos erosivos do IPT (2012). O mapa de declividade foi gerado a partir dos dados topográficos com curvas de nível de 20 em 20 metros (ZUQUETTE, 1987; FLORENZANO, 2008). A sistemática adotada no trabalho envolveu cinco etapas principais, como se observa na Figura 2. 
Figura 2 - Fluxograma das etapas de trabalho com os pesos atribuídos as variáveis

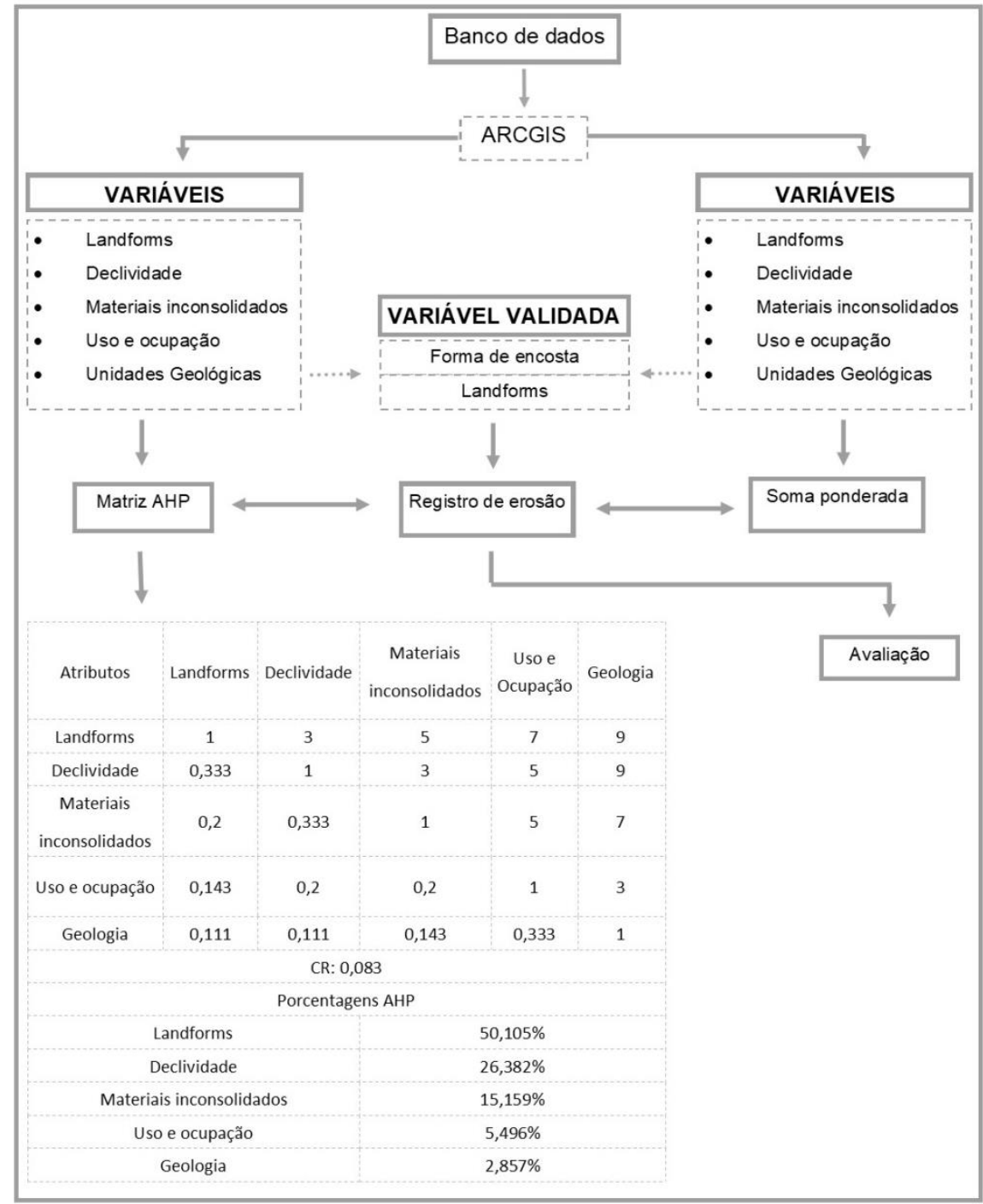

Fonte: Elaborada pelos autores.

Com a definição do suporte cartográfico, foi elaborada a base de dados no ArcGIS 10.4 (ESRI, 2017), para a geração das cartas derivadas e dos mapas temáticos. A Figura 3 apresenta os cartogramas dos atributos ambientais. 
Figura 3 - Documentos cartográficos que compõem as variáveis ambientais da área: A Mapa de Landforms; B - Carta de Declividades; C - Mapa de Substrato Rochoso; D - Carta de Uso e Ocupação das Terras; E - Mapa de Materiais Inconsolidado

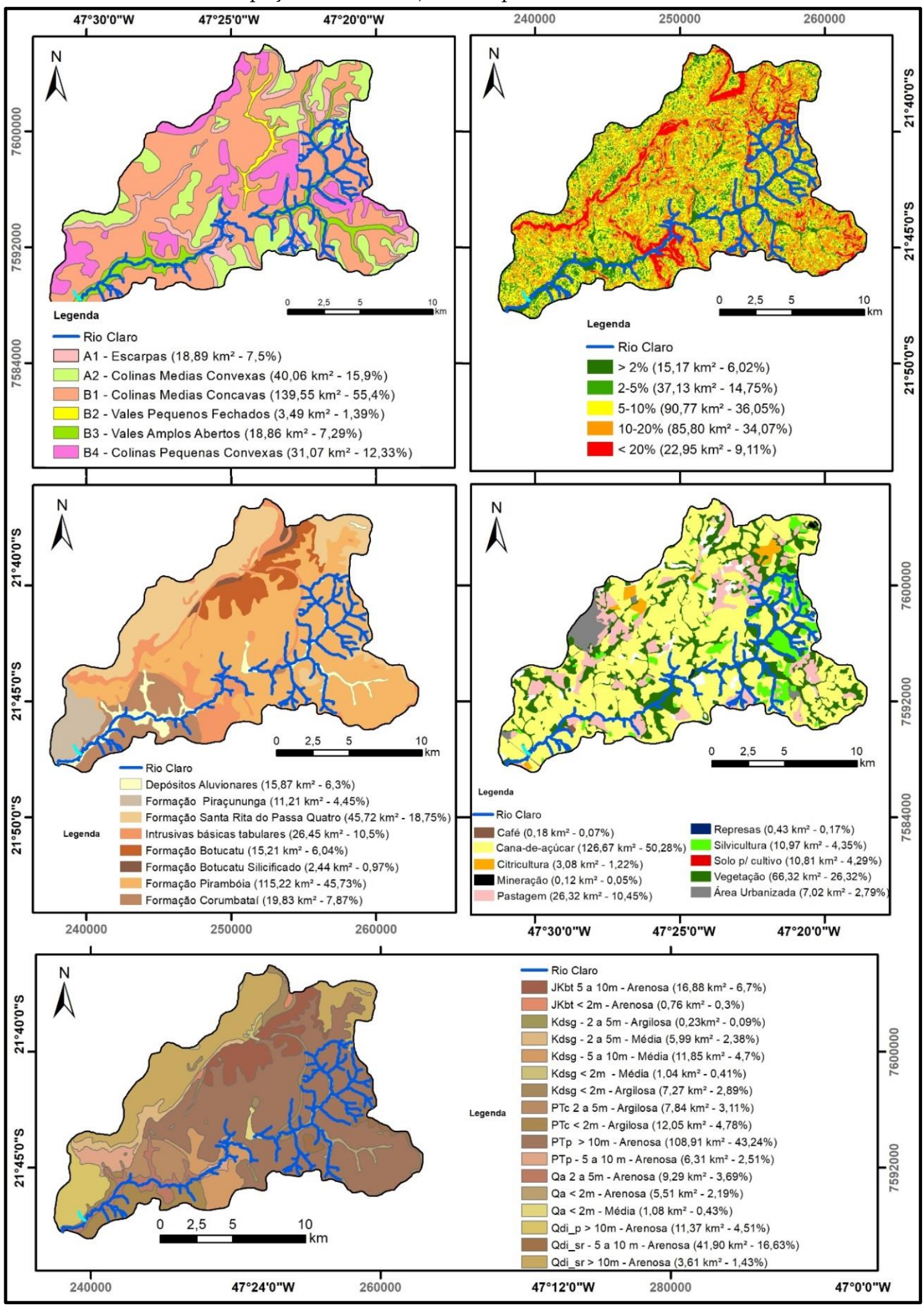

Fonte: Elaborado pelos autores. 
A partir da combinação dos dados dos dados anteriormente apresentados, a suscetibilidade a erosão foi classificada com a aplicação das técnicas de Processo Analítico Hierárquico e Soma Ponderada, segundo cinco classes, variando de muito baixa a muito alta suscetibilidade.

O Processo Analítico Hierárquico (AHP) foi desenvolvido por Thomas Saaty, na década de 70, que propôs a criação de uma hierarquia de decisão para ponderação dos atributos, na qual o primeiro passo é a definição da importância relativa entre as evidências.

Este método é fundamentado na lógica de comparação par a par, onde diferentes fatores influenciam na tomada da decisão. Esses fatores são organizados hierarquicamente e comparados entre si, conforme uma escala predeterminada (1-9) por Saaty (1990), onde o valor 1 equivale à importância igual entre os fatores e o valor 9, a importância extrema de um fator sobre o outro. Saaty (1994) ressalta que o julgamento das comparações prioritárias é baseado em intuição, experiência e dados quantitativos e qualitativos.

Em um trabalho desenvolvido por Rowley et al. (2012) foram analisados métodos multicritério como a Soma Ponderada, AHP, SMART, TOPSIS, MACBETH, ELECTRE, PROMETHEE aplicados em problemas ambientais que envolvem sustentabilidade. Os autores destacam a importância da escolha do método multicritério, pois uma escolha feita erroneamente pode comprometer toda a definição de pesos e agregação, gerando subjetividade e incerteza.

Nessa visão, a Soma Ponderada é usada para formular um julgamento abrangente sobre o desempenho de sustentabilidade em relação às demais alternativas.

Dentre os métodos desenvolvidos para otimização multiclasses, o mais empregado e de uso mais simples é o método da soma ponderada (Weighted Sum Method - WS) (KOSKI, 1985; AFONSO, 1997; MOTTA et al., 2012). A técnica se baseia em atribuir um vetor de coeficientes de ponderação às classes normalizadas, combinando-as linearmente, ou seja, transformando-as 
em uma única classe. Em geral, quando se utiliza essa metodologia, ocorre uma distribuição uniforme dos pesos.

Para o cruzamento dos documentos cartográficos obtidos neste estudo, foi utilizada a ferramenta Weighted Sum, do ArcGis 10.4 (ESRI,2017), que de acordo com Capistrano Filho (2011) é uma ferramenta que possibilita atribuição de pesos e importância relativa aos arquivos matriciais e a combinação de múltiplos fatores, possibilitando, assim, uma análise integrada.

\section{Resultados e discussões}

Considerando as cartas de suscetibilidade à erosões, obtidas no presente trabalho (Figura 4), observa-se que as áreas classificadas como suscetibilidade alta e muito alta representam percentuais pouco significativos da área da bacia do Rio Claro (0,61\% na carta obtida a partir da aplicação da AHP, e $0,45 \%$ na carta obtida com a soma ponderada - WS).

As parcelas da bacia classificadas como média suscetibilidade à erosão (3,34\% para AHP, e 3,77\% para carta gerada por WS) também representam parcelas pequenas da bacia. As classes predominantes na classificação são "muito baixo" e "baixo" potencial (totalizando 96,05\% no caso da AHP, e 95,79\% no caso da WS).

Se a maior parte da bacia se enquadra nas classes de muito baixa a baixa erodibilidade segundo os métodos consagrados para geração de tais cartas, faltava explicar como os 127 processos erosivos registrados na área $\left(0,504\right.$ processos $\left./ \mathrm{km}^{2}\right)$ foram condicionados. Uma abordagem aplicada a princípio foi à verificação da relação entre a classificação e os atributos considerados.

As áreas de altas declividades se concentram no relevo de escarpas, onde ocorrem perfis de solo rasos e materiais resistentes à erosão (intrusivas 
básicas e arenitos silicificados da Formação Botucatu) não apresentando um número expressivo de feições erosivas.

Figura 4 - Suscetibilidade à erosão segundo os métodos AHP e WS

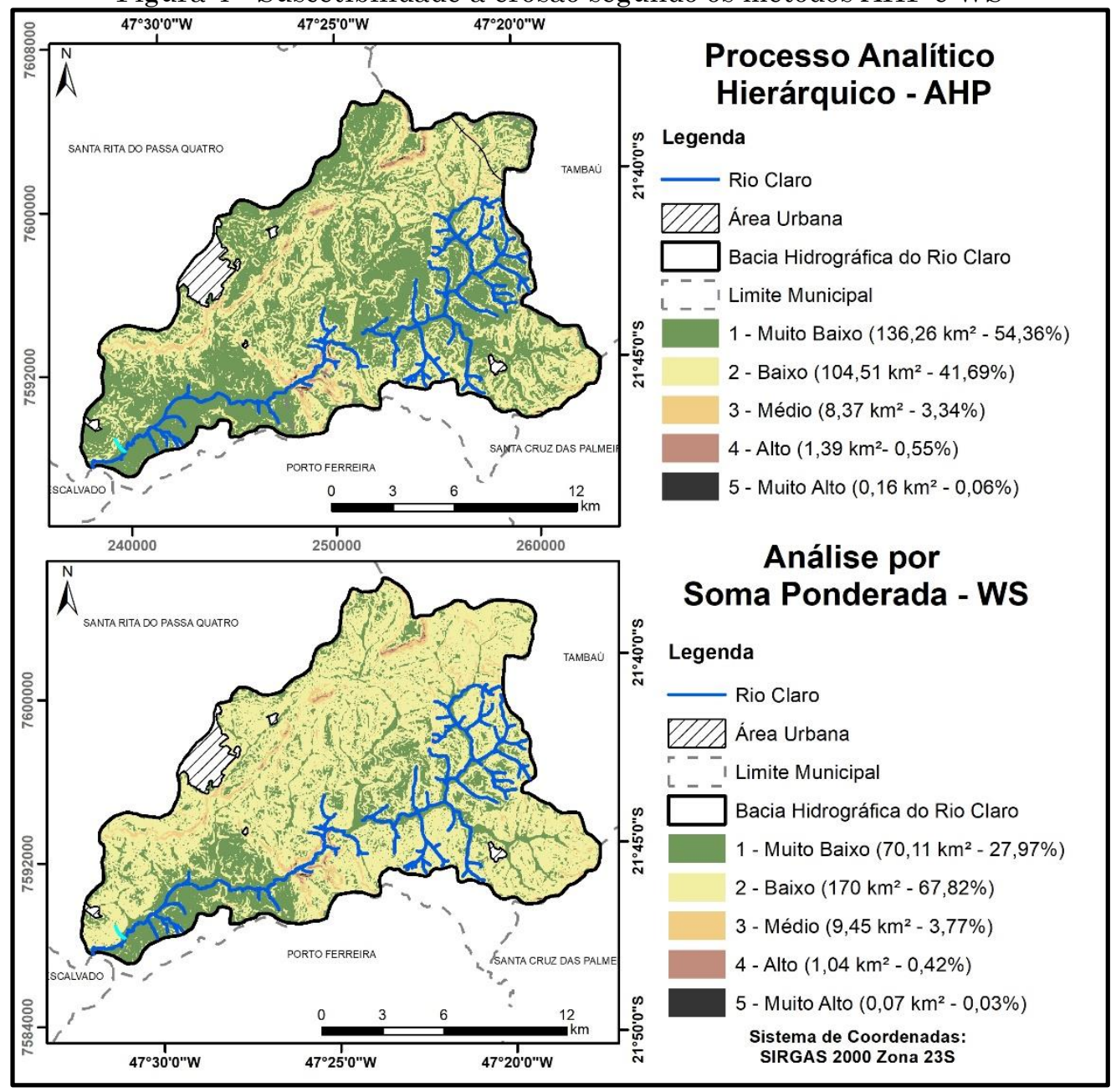

Fonte: Elaborada pelos autores.

A suscetibilidade à erosão se manifesta nas áreas de expansão urbana, fruto da impermeabilização de parcelas do solo, com alterações no regime de escoamento superficial e tempo de retenção das águas pluviais, além do direcionamento do fluxo da água pelo sistema de drenagem urbana. Ressaltase que a área urbanizada se encontra consolidada, com alto grau de impermeabilização, razão pela qual não foi mapeada na presente análise.

Nos resultados de classificação da suscetibilidade à erosão a partir do processo analítico hierárquico se observa predominância de regiões 
classificadas como muito baixa suscetibilidade em relação às de baixa, ao contrário do que se constata na carta temática resultante do processo de soma ponderada (Figura 4). Com relação às áreas classificadas de média a muito alta suscetibilidade, não são observadas diferenças muito significativas entre os resultados obtidos pelos dois processos de classificação. Em geral, se observa forte predominância das classes de suscetibilidade muito baixa e baixa em relação às demais. Porém, devido à quantidade de registros de erosões na região, verificou-se a necessidade de uma análise mais detalhada dos dados.

Considerando o total dos registros de processos erosivos (127) identificados na bacia do Rio Claro por IPT (2012), se observam distribuições diferentes em função dos atributos ambientais considerados na análise: (1) substrato rochoso; (2) materiais inconsolidados; (3) landforms; (4) declividade; e (5) uso e ocupação.

Com relação às unidades de materiais inconsolidados, se observa que a unidade PTp (solos residuais da Formação Pirambóia) contém 48,03\% dos processos erosivos registrados na área, enquanto a unidade Santa Rita (Qdi_sr) representa 21,26\% e a unidade Botucatu (JKbt) 11,02\%.

No entanto, quando se considera a densidade de processos erosivos por quilômetro quadrado de área, se observa uma densidade 0,53 processos $/ \mathrm{km} 2$ para a unidade Pirambóia, 0,59 \% processos/km2 para unidade Santa Rita, e 0,79 processos $/ \mathrm{km} 2$ para unidade Botucatu. De fato, o alto percentual de processos erosivos na unidade Pirambóia é reflexo de ser essa a unidade com maior ocorrência na bacia ( $43,2 \%$ da área).

Ao se avaliar a relação entre os registros e as espessuras dos perfis de materiais inconsolidados, se observa que $67,72 \%$ das erosões ocorrem em áreas de perfis com espessura maior do que $10 \mathrm{~m}$, e 20,47\% em perfis com espessuras entre 5 e $10 \mathrm{~m}$. Em termos de densidade, a classe de espessura maior que $10 \mathrm{~m}$ apresenta densidade de 0,69 processos $/ \mathrm{km}^{2}$, enquanto a densidade média para toda a bacia é 0,38 . 
Com relação à textura dos materiais inconsolidados, 93,7\% das erosões ocorrem nas unidades de textura arenosa, com uma densidade de 0.51 processos $/ \mathrm{km}^{2}$.

A relação entre o registro dos processos erosivos e as unidades do substrato rochoso praticamente repete o padrão das unidades materiais inconsolidados, mostrando as áreas de formação Pirambóia com 48,82\% dos processos, formação Santa Rita com 20,47\%, e formação Botucatu com 11,02\% dos processos. Em termos de densidade, o padrão também se repete. Enquanto que a formação Pirambóia apresenta 0,54 processos $/ \mathrm{km}^{2}$, a formação Santa Rita apresenta 0,57, e a formação Botucatu 0,8.

Em termos de declividade dos terrenos, a classe de declividade $2-5 \%$ representa $41,7 \%$ da área da bacia; a classe $5-10 \%$ representa $32,3 \%$; e a classe $<2 \%$ mostra o percentual de $15 \%$ da área. As densidades de processos erosivos das classes mais expressivas são 1,43 e 1,25 processos/km2, respectivamente para as classes $2-5 \%$ e $<2 \%$; mostrando como a declividade dos terrenos não é fator determinante para o desenvolvimento de processos erosivos na área.

A relação entre os processos erosivos registrados e as classes de uso e ocupação mostra que a maioria dos processos se localiza nas áreas de cultivo de cana de açúcar (49,61\%). Porém, também se observa percentual significativo (33,86\%) dos processos em áreas de vegetação natural. As áreas de cultivo de cana de açúcar exibem densidade de 0,5 processos/ $/ \mathrm{km} 2,0,65$ nas áreas de vegetação natural e 1,3 processos/km2 nas áreas de citricultura.

Considerando os landforms, se tem um percentual bastante significativo (60,6\%) dos processos nas áreas de colinas médias côncavas, e 19,7\% nas colinas médias convexas. Esse aparente contrassenso é desmistificado quando este se calcula as densidades dos processos por unidades de landform. Enquanto as colinas côncavas mostram densidade de 0,55 processos $/ \mathrm{km}^{2}$, as colinas convexas apresentam densidade de 0,72.

Apesar das evidentes relações entre a textura arenosa dos solos que são materiais residuais das unidades do substrato de litotipos arenosos, e de uma 
parcela significativa de processos ocorrendo em áreas de uso agrícola; respostas esperadas em casos assim; a explicação para os processos erosivos na bacia não fica bastante evidente apenas com base nesse conjunto de informações.

Por essa razão, e considerando as classes de landforms com maior concentração de registros de processos erosivos, buscou-se verificar a relação entre a forma dos perfis das encostas e a erosão.

Os dados mostram que $70,9 \%$ das erosões se situam em áreas de encostas com perfis divergentes (Figura 5). Destes, a maior parcela (45,7\%) ocorre em áreas de encostas divergentes retilíneas; 18,1\% ocorrem em encostas divergentes côncavas; e 7,1\% ocorrem na forma divergente convexa.

Figura 5 - Mapa de associação entre feições erosivas e formas de encosta

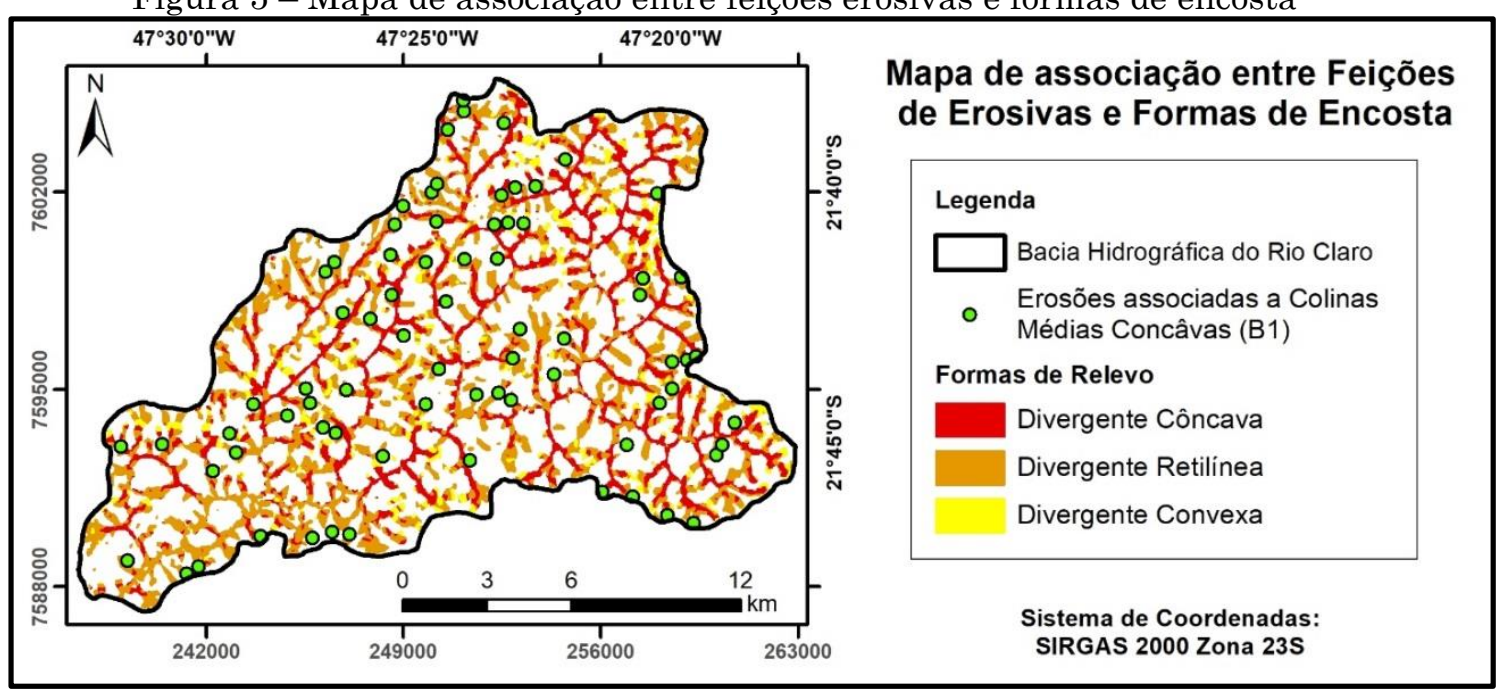

Fonte: Elaborado pelos autores.

Quando se observa a distribuição dos processos em termos densidade, se verificam densidades de 1,38 processos $/ \mathrm{km}^{2}$ nas encostas divergentes convexas; 1,34 nas divergentes retilíneas, e 0,63 processos $/ \mathrm{km}^{2}$ nas formas divergentes côncavas. Indicando que, dentre as encostas divergentes, que concentram a maioria dos processos erosivos na bacia, as formas convexas e retilíneas têm maior influência na ocorrência de erosões. 


\section{Conclusões}

O registro de feições erosivas foi fundamental na avaliação dos processos e atributos na bacia hidrográfica do Rio Claro e a sua distribuição, permitindo a interpretação das Cartas Temáticas AHP e WS e comparações entre os resultados dos dois métodos em função dos atributos considerados.

Os processos erosivos cadastrados estão em estado ativo, degradando porções extensas da bacia, associadas principalmente às áreas de menores declividades (2 e 10\%), em áreas de depósitos sedimentares quaternários e solos residuais arenosos das formações terciárias.

Os resultados mostram forte concentração de processos erosivos em áreas classificadas como suscetibilidade baixa e muito baixa segundo as duas técnicas, em particular nas áreas de colinas médias côncavas e convexas, com setenta e quatro dos cento e vinte e sete registros localizados nessas encostas.

A concentração de feições erosivas é controlada essencialmente pela forma das encostas, particularmente nas áreas de colinas médias divergentes, sendo mais comuns nas formas divergentes côncavas. Porém, os processos erosivos ocorrem de formas mais concentrada nas formas divergentes convexas e, secundariamente nas formas divergentes retilíneas; em perfis de alteração de solos arenosos espessos e de baixa compacidade.

\section{Agradecimentos}

Os autores agradecem a Fundação de Amparo à Pesquisa do Estado de São Paulo, pela concessão de recursos financeiros, aportados ao Processo $n^{\circ}$ 2013/03699-5, os quais possibilitaram a geração de resultados laboratoriais essenciais na elaboração deste trabalho e informam que "o presente trabalho foi realizado com apoio da Coordenação de Aperfeiçoamento de Pessoal de Nível Superior - Brasil (CAPES) - Código de Financiamento 001”. 


\section{Referências}

AFONSO, S. M. B. Structural Shape Optimization Considering Multiobjective Functions. In: Proceedings of III SIMMEC - III Simpósio Mineiro de Mecânica Computacional, Ouro Preto(MG), 1997. pp. 251-260.

BITAR, O. Y. Guia Cartas geotécnicas [livro eletrônico]: orientações básicas aos municípios. Autores e organizadores: Omar Yazbek Bitar, Carlos Geraldo Luz de Freitas, Eduardo Soares de Macedo. -- São Paulo: IPT - Instituto de Pesquisas Tecnológicas do Estado de São Paulo, 2015. Disponível em: <www.ipt.br/guia_cartas_geotecnicas.pdf>. Acesso: 10 de novembro de 2017.

CAPISTRANO FILHO, G. W. Identificação de áreas não antropizadas no Distrito Federal favoráveis a amostragem de solo visando o estabelecimento do Valor de Referência de Qualidade - VQR. In: Simpósio Brasileiro de Sensoriamento Remoto, 7, 2011, Curitiba. Anais. Curitiba, 2011. INPE. 2011. p. 7206

COSTA, C.W.; MOSCHINI, L.E.; LORANDI, R. Aquisição de dados geográficos em plataformas livres para estudos ambientais em bacias hidrográficas. In: Maria Eugênia Bruck de Moraes \& Reinaldo Lorandi. (Org.). Aquisição de dados geográficos em plataformas livres para estudos ambientais em bacias hidrográficas. 1ed. Ilhéus - BA: Editus - Editora da UESC, 2016, vol. 1, 2016. pp. 15-34.

COSTA, C.W.; LORANDI, R.; LOLLO,J.A.; IMANI,M.; DUPAS,F.A. Surface runoff and accelerated erosion in a peri-urban wellhead area in southeastern Brazil. Environmental Earth Sciences, vol. 77, n. 160, 2018.

DORICI, $\mathrm{M}$ et al. Accelerated erosion in a watershed in the southeastern region of Brazil. Environmental Earth Sciences, Springer-Verlag Berlin Heidelberg, 2016.

ESRI 2017. ArcGIS Desktop: Release 10.4. Redlands, CA: Environmental Systems Research Institute. 2017

FUNDO ESTADUAL DE RECURSOS HÍDRICOS (FEHIDRO). Plano da Bacia Hidrográfica: 2008-2011. Comitê da Bacia Hidrográfica do Rio Mogi Guaçu, CETESB - São Paulo. 2011. 170p. 
FLORENZANO, T. G. Geomorfologia: conceitos e tecnologias atuais. São Paulo, Oficina de Textos, 2008. 320p.

GALHARTE, C.A.; VILLELA, J.M.; CRESTANA, S. Estimativa da produção de sedimentos em função da mudança de uso e cobertura do solo. Revista Brasileira de Engenharia Agrícola e Ambiental, vol. 18, n. 2. 2014. pp. 194-201.

GARCIA, Y. M. Aplicação do Código Florestal como subsídio para o planejamento ambiental na bacia hidrográfica do Córrego do Palmitalzinho - Regente Feijó - São Paulo. Trabalho de Conclusão (Bacharelado - Geografia) - Universidade Estadual Paulista, Faculdade de Ciências e Tecnologia - Presidente Prudente, 2011. 145p.

GUERRERO, J. V. R.; LORANDI, R.; LOLLO, J. A. Cartografia Geoambiental como Base para Planejamento Territorial na Bacia do Rio Clarinho, SP. Revista Brasileira de Cartografia, vol. 68, n. 2, 2016. pp. 313-326.

HE X, ZHOU J, ZHANG X \& TANG K. Soil erosion response to climatic change and human activity during the Quaternary of the Loess Plateau, China. Regional Environment Change, 2006. pp. 62-70.

INSTITUTO FLORESTAL DO ESTADO DE SÃO PAULO (IF). Inventário Florestal do Estado de São Paulo. São Paulo: Secretaria de Estado do Meio Ambiente. 2010

INSTITUTO BRASILEIRO DE GEOGRAFIA E ESTATÍSTICA (IBGE). Cartas topográficas. Folhas Topográficas de Santa Rita do Passa-Quatro; Luiz Antônio, e Descalvado. Escala 1:50.000, 1971.

INSTITUTO DE PESQUISAS TECNOLÓGICAS DO ESTADO DE SÃO PAULO.

Cadastramento de pontos de erosão e inundação no Estado de São Paulo. Relatório Técnico. 4.v., 2012. pp. 057-205.

KOSKI, J. Defectiveness of Weighting Method in Multicriterion Optimization of Structures. s.l.:s.n. 1985.

LAL, R. Soil degradation by erosion. Land Degration and Development, vol. 12, 2001. pp. 519-539.

LOLLO, J. A.; SENA, J. N. Estabelecimento de suscetibilidade a erosão diferentes técnicas para diferentes etapas de tomada de decisão. 
AUGMDOMUS, Asociación de Universidades Grupo Montevideo, Uruguai, vol. $5,2013$.

LORANDI, R.; LOLLO, J.A. Zoneamento Geoambiental Analítico da Bacia do Rio Claro (SP) na escala 1:50.000. Relatório Final de Pesquisa. UFSCar/FAPESP, 2016.

MENDONÇA, F; DANNI-OLIVEIRA, I.M. Climatologia: noções básicas e climas do Brasil. Oficina de textos. São Paulo. 2007.

MENEZES, D. B. Avaliação de aspectos metodológicos e aproveitamento de informações do meio físico em estudos geoambientais de bacias hidrográficas: aplicação na Bacia do Rio Pardo. Tese (Doutorado em Geociências e Meio Ambiente) - Instituto de Geociências e Ciências Exatas, Universidade Estadual Paulista "Júlio de Mesquita Filho", Rio Claro. 2001. $235 p$.

MONTES, L.M.V.; RUIZ, A.M. Environmental indicators to evaluate spatial and water planning in the coast of Granada (Spain). Land Use Policy, vol. 25, n. 95. 2008.

MORAES, M. E. B. et al. A legislação Ambiental da bacia do rio Claro (São Paulo). 1ed.Ilhéus - BA: Editus - Editora da UESC, 2016, vol. 13, 2016. pp. 263-274.

MOTTA, R. D. S., AFONSO, S. M. B. \& LYRA, P. R. M. A modified NBI and NC method for the solution of $\mathrm{N}$-multiobjective optimization problems. s.l.: Springer. 2012.

PEJON, O.J. Mapeamento geotécnico regional da Folha de Piracicaba (SP) escala 1:100.000: estudo de aspectos metodológicos, de caracterização, e de apresentação de atributos. Tese (Doutorado em Geotecnia) - Escola de Engenharia de São Carlos, Universidade de São Paulo, São Carlos. 1992. 244p. PONS, N.A.D.; PEJON, O.J.; ZUQUETTE, L.V. Use of Geoprocessing in the study of land degradation in urban environments: the case of the city of São Carlos, state of São Paulo, Brazil. Environmental Geology, vol. 53. 2007. pp. 727739.

ROSS, J. L. S.; DEL PRETTE, M. E. Recursos hídricos e as bacias hidrográficas: âncoras do planejamento e gestão ambiental. Revista do Departamento de Geografia, São Paulo, n. 12, 1998. p. 89-122. 
ROWLEY, H. V et al. Aggregating sustainability indicators: Beyond the weighted sum. Journal of Environmental Management, vol. 111, 2012. pp. 24 - 33. SAATY, T.L. Multicriteria Decision Making. The Analytic Hierarchy Process: Planning, Priority, Setting, Resource Allocation. 2. ed.Pittsburgh: RWS Publications, 1990.

SAATY, Thomas L. How to make a decision: the analytic hierarchy process. Interfaces, v. 24, n. 6, 1994. p. 19-43.

SCHEWE, J. et al. Multimodel assessment of water scarcity under climate change. Proceedings of the National Academy of Sciences of the United States, vol. 111, n. 9. 2014. pp. 3245-3250.

TAGLIARINI, F. S. N. et al. Avaliação morfométrica da microbacia do Córrego do Bebedouro, Planalto - SP. Energia na Agricultura, Botucatu, vol. 30, n. 4, 2015. pp. 402-410.

TORRES, I.C., LEMOS, R.S.; MAGALHÃES JUNIOR, A.P. Influence of the Rio Taquaraçu in the water quality of the Rio das Velhas: subsidies for reflections of the case of water shortage in Belo Horizonte metropolitan region - MG, Brazil. Revista Brasileira de Recursos Hídricos, vol. 21, n. 2. 2016. pp. 429-438.

ZUQUETTE, L. V. Análise crítica da cartografia geotécnica e proposta metodológica para condições brasileiras. Tese (Doutorado em Geotecnia) - Escola de Engenharia de São Carlos - Universidade de São Paulo, São Carlos, 1987. 219p. 